\title{
Uma história do futebol feminino nas páginas da Revista Placar entre os anos de 1980-1990
}

\author{
Leila Salvini* \\ Wanderley Marchi Júnior
}

\begin{abstract}
Resumo: O presente artigo tem como objetivo apresentar uma história do futebol feminino contada pelas páginas da revista Placar entre os anos de 1980-1990. Foram mapeados 457 exemplares, destes, 8 foram utilizados para desenvolver esse artigo. Após a análise dos dados, notamos que nessa década três principais informações sobre o futebol feminino foram veiculadas na revista: 1.) permissibilidade da prática do futebol pelo público feminino; 2) a habilidade feminina para jogar futebol, frisando principalmente o surgimento a performance do Esporte Clube Radar; e 3) um tema que permeia os elementos anteriores e é recorrente nessa fase da revista, são as matérias que exaltam as características de feminilidade normativa nas jogadoras de futebol.
\end{abstract}

Palavras Chave: Futebol Feminino. Revista Placar. História do Futebol Feminino.

\section{INTRODUÇÃo}

As manifestações físicas e esportivas direcionadas ao público feminino em meados do século XX registram preocupações com a promoção e a manutenção de um corpo "feminino" e saudável. O exercício físico, em meio a essa conjuntura de renovação populacional pela qual passava a sociedade brasileira, tinha papel de desenvolver a força física e a saúde como atributos para a formação de uma mãe robusta e reprodutiva que pudesse produzir gerações mais fortes e saudáveis (MOURÃO, 2000). Salientamos que "nos anos 30 e 40,

\footnotetext{
'Mestre em Educação Física pela Universidade Federal do Paraná, Curitiba, PR, Brasil. E-mail: leila.salvini@hotmail.com

"Professor de graduação e pós-graduação na Universidade Federal do Paraná, Curitiba, PR, Brasil.E-mail: marchijr@ufpr.br
} 
a associação entre o autoritarismo político e as idéias e ideais da eugenia fazia do corpo uma questão de Estado e o colocava na ordem do dia" (FRANZINI, 2005, p. 321).

Contudo, nem todas as práticas físicas e/ou esportivas eram indicadas e adequadas às mulheres. Goellner (1999, 2003, 2005) assinala que somente àquelas práticas que visam o reforço de características feminis como a delicadeza do corpo e dos gestos, a inexistência de contato direto com o oponente e que não prejudicassem seu desenvolvimento anatômico e fisiológico, como a dança, a ginástica e a natação, eram indicadas.

Nesse contexto de determinações indiretas que visavam à construção de papeis sociais por meio da manipulação das práticas esportivas e por consequência dos corpos e das ações práticas de seus agentes, o futebol feminino apresenta-se como um "desvio de conduta", pois proporcionava às mulheres outras possibilidades 1 "além daquelas consagradas pelo estereótipo da 'rainha do lar', que incensava a 'boa mãe' e a 'boa esposa' (de preferência seguindo os padrões hollywoodianos de beleza), principalmente, restrita ao espaço doméstico" (FRANZINI, 2005, p. 321).

Somando-se aos modos indiretos de limitar as práticas esportivas femininas, no ano de 1941, foi instituído o Decreto-Lei $3.199^{2}$ que em seu artigo 54 estabelecia que: "às mulheres não se permitirá a prática de desportos incompatíveis com as condições de sua natureza devendo, para este efeito, o Conselho Nacional de Desportos (CND) baixar as necessárias instruções às entidades desportivas do país".

Em plena ditadura militar no ano de 1965, tal Decreto-Lei foi implementado pelo CND, passando assim, a proibir a prática feminina

\footnotetext{
${ }^{1}$ As outras possibilidades concedidas às mulheres, dizem respeito à saída do espaço doméstico e a ocupação (mesmo que limitada) do espaço público, incluindo as práticas esportivas. Nesse contexto salientamos que o futebol masculino está arraigado à cultura brasileira ao ponto que muitos estudiosos (dentre os quais citamos: Arlei Damo, 2002 e Luiz Henrique Toledo, 2000) consideram-no como parte da identidade nacional, logo, em uma sociedade sexista como a nossa, a prática do futebol pelo público feminino apresentava-se como uma "afronta".

${ }^{2} O$ inteiro teor do decreto pode está disponível em: <http://www6.senado.gov.br/legislacao/ ListaPublicacoes.action?id=152593>. Acesso em: 9 set. 2010. E foi revogado no ano de 1975 pela lei 6251/75, disponível em: <http://www3.dataprev.gov.br/SISLEX/paginas/42/1975/ 6251.htm>. Acesso em 09 set 2010.
} 
de lutas de qualquer natureza, a saber, futebol, futebol de salão, futebol de praia, pólo aquático, pólo, rugby, halterofilismo e baseball.

Mesmo com as proibições legais, as mulheres continuavam (em número restrito) jogando o futebol em diferentes regiões do nosso país, como podemos identificar no estudo de Rigo et al. (2008) sobre o futebol feminino na cidade de Pelotas-RS no ano de 1950. Esses autores afirmam que o futebol feminino

passou a ser visto pelo CND como um prática ilícita
somente quando deu sinais de que poderia
estruturar-se como uma modalidade esportiva
feminina, conquiastando mais autonomia perante
os homens e fazendo reivindicações que até então
eram restritas ao futebol masculino. O CND "entrou
em campo" e fez com que a lei fosse cumprida,
antes que fosse tarde demais, quando aquelas
experiências isoladas passaram a representar um
afronte aos costumes sociais da época que
restringiam a mulher ao espaço privado, vigiavam a
vestimenta e disciplinavam o seu corpo feminino.
Nesse sentido construiu-se odiscurso que a prática
do futebol não era condizente com a mulher -
principalmente se jogado com chuteiras! (RIGO et.
al, 2008 p. 183).

A revogação do Decreto aconteceu no final dos anos 1970. No entanto, os valores culturais incorporados e reproduzidos sobre a perda ou a diminuição da feminilidade das mulheres praticantes da modalidade, não foram "instantaneamente" revogados. A permissão legal da prática do futebol feminino estava aí, mas grande parte da criação e do gerenciamento dessas novas equipes ficava - e atualmente ainda fica - sob o encargo dos homens.

Em meio a essa "nova" situação que se instaurou na década de 1980 no nosso país, instigamo-nos, a conhecer quais eram as informações veiculadas nas revistas esportivas, ou mais precisamente, na revista Placar sobre o futebol feminino. Dessa forma, o presente artigo tem como objetivo apresentar uma história do futebol feminino contada pelas páginas da revista Placar entre os anos de 1980 a 1990.

Movimento, Porto Alegre, v. 19, n. 01, p. 95-115, jan/mar de 2013. 
A coleta das informações foi realizada por meio de busca pela palavra-chave: "futebol feminino". Após mapearmos as edições que contemplavam nossa busca, elencamos as notícias que apresentavam maior número de informações, bem como, selecionamos algumas imagens que vem a somar à apresentação desses dados. As revistas que serviram de base para a pesquisa estão disponíveis online ${ }^{3}$, datam os anos de 1980 até 1990 e totalizam 457 exemplares. Destes, 8 foram utilizados para desenvolver esse trabalho.

Justificamos a escolha da revista Placar como fonte de dados por entender que é a revista de esportes que há mais tempo vem sendo comercializada no Brasil, e que, embora veiculasse (até meados dos anos 1990) informações sobre todos os esportes, tinha no futebol seu "carro chefe".

O presente artigo está organizado pela ordem de aparição das informações nos exemplares da revista, e se subdivide basicamente em dois tópicos: primeiro apresentaremos algumas notas sobre a proibição do futebol feminino. Na sequencia, traremos apontamentos das matérias da revista que abordam a habilidade da mulher jogadora de futebol materializada no desempenho do Esporte Clube Radar, bem como, a exaltação das características normativas do gênero feminino nas jogadoras.

\section{NOTAS SOBRE A PROIBIÇÃO DO FUTEBOL FEMININO}

Fundada no início dos anos 1970 com o escopo de divulgar matérias de diferentes modalidades esportivas, tiragem semanal e circulação nacional, a revista Placar tinha uma sessão dedicada à opinião dos leitores. Recebia nessa época - final dos anos 1970 e início dos anos 1980 - alguns comentários de mulheres simpatizantes ou praticantes de esportes considerados como "não femininos". As falas invariavelmente abordavam questões relacionadas à proibição da prática do futebol, bem como, meninas procurando locais onde

\footnotetext{
${ }^{3} \mathrm{O}$ acervo de revistas Placar está arquivado no site Google Books, disponível no seguinte link: <http://books.google.com.br/books/about/Placar_Magazine.html?id=ex_jY90gyh8C\&redir _esc=y> Acesso em: 21 out. 2012.
} 
treinar ou com o ensejo de montar equipes, como podemos visualizar no trecho extraído da revista Placar de 5 de setembro de 1980, p. 66:

Figura 1 - Recorte da Revista Placar

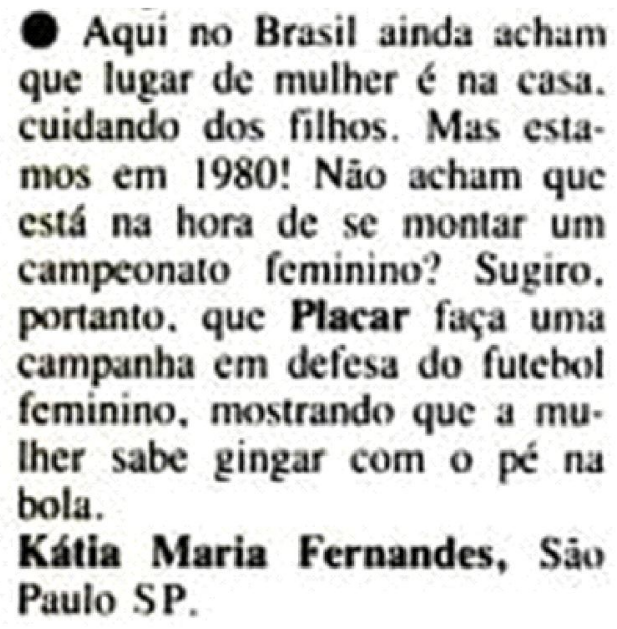

Fonte: Revista Placar, 5 set. 1980.

Nessa mesma sessão, na edição número 594 de 2 outubro de 1981 foi lançada uma enquete com duas questões: "Você é a favor do futebol feminino?" e "Você chegaria mais cedo ao estádio só para ver uma preliminar ${ }^{4}$ entre dois times de mulheres?" Essa enquete (ilustrada a seguir) foi veiculada nas edições de 25 de setembro e 2 de outubro de 1981 .

\footnotetext{
${ }^{4}$ Prática comum aos times femininos, a preliminar corresponde ao jogo de abertura realizado pelas mulheres para anteceder as partidas masculinas.
} 
Figura 2 - Recorte da Revista Placar

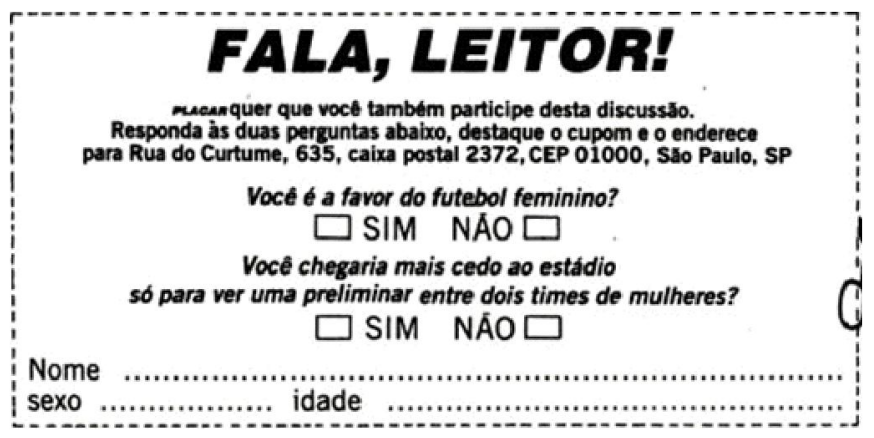

Fonte: Revista Placar, 25 set. 1981.

A edição de 2 de outubro de 1981 já apresentava algumas respostas a enquete, fomentando a participação de uma grande maioria de mulheres, as quais, levantaram a bandeira em defesa da sexualidade e feminilidade das futebolistas. Como ilustra o recorte a seguir:

Figura 3 - Recorte da Revista Placar

\section{Minha \\ Opimīano}

É com imenso prazer que estou participando da discussấo sobre o futebol feminino, promovida por nucar E gostaria de além de votar - dar também minha opiniảo sobre o assunto. Se o esporte foi feito para ambos os sexos, acho que cada um tem o direito de eseolher o scu. Eu, por exemplo, gosto de jogar futebol e handebol. e adoro fazer Cooper. Apesar de jogar futebol, me considero muito feminina.
Quem diz que a mulher que joga futebol 6 homossexual está super enganado, pois nós somos tho mulheres como as que nato o praticam. Respondam sim à consulta de rucan. Ajudem-nos a mostrar que o nosso futebol tem muita graça.

Carla Torres

Brasilia, DF

E a opinido da Carla. Aproveitando, aí vai mais um cupom da pesquisa que nucan está fazendo. Fala, leitor!

Fonte: Revista Placar 2 out. 1981 
Ainda que não houvesse nada explicito no corpo da revista, elementos que ligavam o futebol à "perda" da feminilidade vinham sendo impregnados na cultura e nas ações práticas dos agentes desde o princípio da década de 1940 , fato que se materializava nas publicações esportivas. Percebemos também que a revista custou a divulgar explicitamente os "novos" rumos do futebol feminino no Brasil, e quando os fez, vinculou a figura da futebolista à feminilidade, como verificaremos na sequência.

Dentre as novas orientações está a proibição das trocas de camisas entre as jogadoras e o uso de chuteiras com travas metálicas; os jogos terão duração de 70 minutos com 20 minutos de intervalo; as bolas serão mais leves e as dimensões do campo menores. Com relação às categorias, o CND estabeleceu a existência de duas categorias: juvenil, de 14 a 18 anos, e adulta, acima de 18. Exceto pelo número de substituições - as meninas poderão trocar três jogadoras durante a partida - o restante das regras permanece as mesmas adotadas para os homens (BOLA..., 1983, p. 68).

Embora campeonatos regionais e estaduais já viessem sendo disputados desde 1981, como o evento carioca de 1983 que foi o primeiro campeonato de futebol feminino organizado pela Federação de Futebol do Rio de Janeiro nas categorias juvenil e adulto (FERNANDES, 1991), a veiculação de informações diretamente ligadas a modalidade em sua instância feminina, era bastante reduzida. Vale destacar que para a revista Placar o Decreto só foi revogado no ano de 1981 e não em 1979 como provam os documentos oficiais, fato que pode fundamentar, de certa forma, o atraso na divulgação do futebol feminino.

No item a seguir, propomo-nos a identificar e a descrever quais foram as primeiras matérias da revista Placar envolvendo o futebol feminino. 


\section{HABILIDOSA, PORÉM FEMININA}

Mesmo com o atraso da divulgação da liberação da prática do futebol feminino no Brasil pelos meios de comunicação, a popularização da modalidade e especialmente a fundação e desempenho da equipe do Esporte Clube Radar - ilustrada na sequencia-, promoveram a divulgação de matérias a respeito do futebol feminino.

Figura 4 - Equipe do Esporte Clube Radar

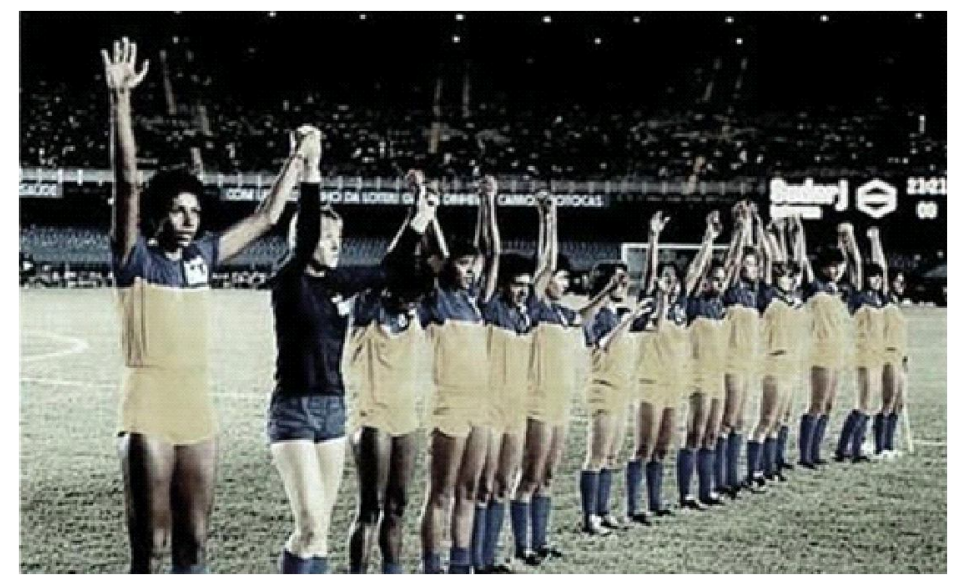

Fonte: Revista Placar, $1^{\circ}$ fev. 1985

O Esporte Clube Radar, um clube de praia de Copacabana, foi fundado em 1932 e em 1981 foi criada a equipe feminina. Inicialmente jogando nas quadras, depois na areia e finalmente no campo, onde teve maior êxito e foi considerado o mais importante clube de futebol feminino (CARMONA; POLL, 2006). O empresário Eurico Lira, fundador da equipe feminina, destaca que juntamente à equipe nasceu a ideia de organização dos times com relação ao treinamento e ao pagamento de salários, bem como, a luta para tornar a modalidade oficial (FUTEBOL..., 1984, p. 24). 
Desse modo, no ano de $1984^{5}$ uma matéria de importância, ou melhor, de capa sobre o futebol feminino brasileiro foi publicada ${ }^{6}$ na revista Placar. Tratando dos principais clubes do país dessa época, a capa da edição n 738 de 13 de julho de 1984 trazia a volante do, atualmente extinto, Pinheiros - PR. A jogadora Vandira trajava a camisa do clube e uma calcinha e a matéria tinha o seguinte chamado: "Futebol Feminino: 3.000 times e 45.000 mulheres em campo", como podemos observar na imagem a seguir:

Figura 5 - Capa da Revista Placar

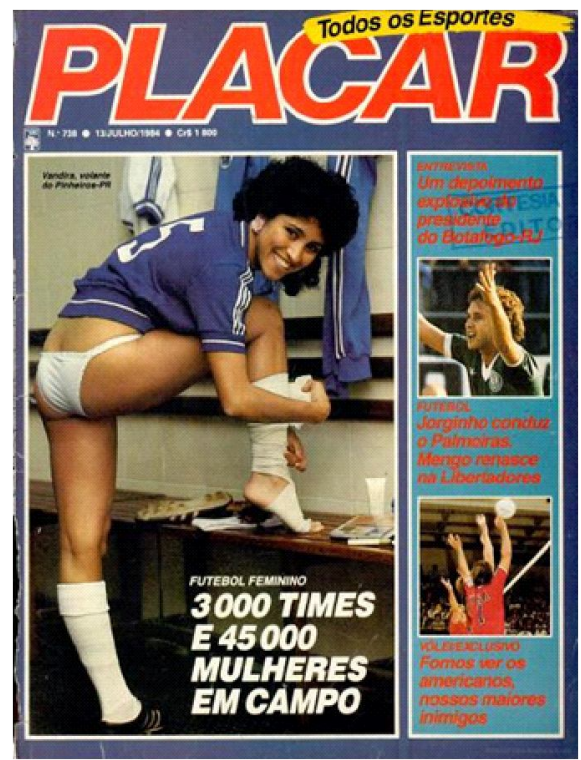

Fonte: Revista Placar, 13 jul. 1984

\begin{abstract}
${ }^{5}$ Houve representativa veiculação de reportagens referentes ao futebol feminino no ano de 1984. Além da revista Placar, a qual estamos abordando com maior detalhamento, a revista Veja também dedicou duas páginas de sua publicação no 811 de 21 de março de 1984, para tratar do Esporte Clube Radar.

${ }^{6} \mathrm{Na}$ edição $\mathrm{n}^{\circ} 509$ de $1^{\circ}$ de fevereiro de 1980 p 34-36, a Revista Placar dedicou três páginas para falar sobre o futebol feminino na Alemanha. A matéria intitulada "ACREDITE SE QUISER: FUTEBOL É PARA MULHER", foi escrita por Sílvio Rochenback. Vale lembrar que na década de 1970 nos Estados Unidos e na Europa foram criadas ligas de futebol feminino (CARMONA; POLL, 2006, p. 140). Salientamos também que na edição no 673 do dia 15 de abril de 1983, Bete Mendes, atriz e deputada federal pelo PT escreve uma página sobre a liberação do futebol para mulheres num comparativo com a luta das atrizes também para se estabelecerem no espaço que anseiam.
\end{abstract}

Movimento, Porto Alegre, v. 19, n. 01, p. 95-115, jan/mar de 2013. 


\section{ArtigosOriginais}

Mesmo sem menções explícitas de combate à possível "masculinização" da mulher futebolista, nos é possível entender que a imagem "fala por si só", no sentido de induzir o leitor a ler o que "deve" ser lido, ver o que "deve" ser visto e pensar de acordo com as informações fornecidas. Essa relação entre pensamento e velocidade, ou o que Bourdieu (1997, p. 40) chamou de fast-thinkers, "pensadores que pensam mais rápido que sua sombra", se justifica quando o autor aborda que a resposta a esse pensamento rápido são as ideias feitas, "aceitas por todo mundo, convencionais comuns", desse modo, quando essas ideias são compradas pelos leitores é como se o problema estivesse resolvido, numa falsa comunicação, pois ela de fato não existe, sendo que na maioria dos casos a mensagem é vendida, comprada e reproduzida sem maiores questionamentos. Essa "venda de ideias" no presente caso, vem reforçar a normatividade de gênero das jogadoras que acabam de ingressar em uma área até então proibida por lei e carregada de preconceitos que se materializavam no questionamento da sexualidade das jogadoras.

A matéria interna da presente edição escrita por Regina Echeverria e intitulada: "O charme vai a campo", retrata que a modalidade "[...] já é uma definitivamente uma graciosa realidade no país do futebol". A reportagem também tem o intuito de mostrar a existência de equidade entre os gêneros, "[...] como qualquer marmanjo que corra atrás de uma bola, as meninas do futebol recebem vaias, aplausos e muitas cartas, mas também assovios e algumas exclamações de espanto" (FUTEBOL..., 1984, p. 24)7.

A necessidade de atrelar a feminilidade normatizada ao mundo do futebol está na escolha das palavras tanto na chamada quanto no corpo da matéria. Em "a graciosa realidade" ou em "o charme vai a campo" fica perceptível o intento de transpor palavras que remetem à graça e a sedução feminina a esse novo espaço esportivo. Em se tratando da construção dos corpos femininos Goellner (2003, p. 4) ressalta como atributos de corpos feminis, a graciosidade, a harmonia das formas, a beleza, a sensualidade e a delicadeza.

${ }^{7}$ Grifo nosso.

Movimento, Porto Alegre, v. 19, n. 01, p. 95-115, jan/mar de 2013. 
Outro elemento instigante nessa reportagem é que raramente vislumbramos em partidas de futebol masculino assovios e exclamações de espanto, fato que demonstra que embora houvesse um avanço, mascarar as dificuldades e preconceitos ainda era de "primeira necessidade".

Do mesmo modo, essa matéria apresenta de forma relativizada e superada a questão do preconceito quanto à sexualidade das atletas: "[...] as meninas já aprenderam a desligar os ouvidos dos teimosos berros de sapatão, sapatão" (FUTEBOL..., 1984, p. 24).

Além dos temas já abordados pela revista Placar, a revista Veja trouxe à baila um tema que permeia o universo futebolístico desde que as mulheres praticam a modalidade, o homossexualismo. Deveras, com muita discrição e nos parágrafos finais da matéria é mencionado que:

Um tipo de comentário costuma aborrecer a garotas do Radar: o de que o futebol masculiniza a mulher. 'Nenhuma de nós quer se masculinizar', garante a goleira Margareth. 'Queremos continuar a ser mulheres e é como mulheres que temos levado as pessoas aos estádios.' Mais enfática, a quartozagueira Jurema Henrique da Silva, 31 anos, deixa claro que, embora nenhuma das atletas do Radar seja casada, três delas tem noivo e a maioria está namorando. 'Há casos de homossexualismo no futebol feminino', admite, 'mas, afinal, onde não há?' (VEJA, 21 mar. 1984, p. 78).

As jogadoras explicitam (ao explicar sua sexualidade) que estão dentro dos padrões que a normatividade heterossexual impõe para que tanto os jogos quanto as jogadoras sejam atraentes para a mídia. Com relação à veiculação midiática dos jogos, Darido (2002) relata que os jogos realizados pelas equipes femininas eram (nos anos 1980 e continuam sendo atualmente 2011) transmitidos pela Rede 
Bandeirantes de Televisão ${ }^{8}$. Para a autora, a emissora teve papel decisivo no fortalecimento e divulgação desta modalidade no Brasil, e menos na tentativa de romper com o reforço e a reprodução de valores sexistas e discriminadores, e mais pela predominância de interesses econômicos.

Outra demonstração da então inserção do futebol feminino no contexto mercadológico (tendo em vista o - mesmo que breve aumento na demanda de praticantes do futebol) é a criação de uma chuteira especialmente feminina, tanto nos detalhes ergonômicos quanto estéticos. Deste modo, em 1984 a jogadora Bel do Internacional conhecida pela beleza física junto a sua colega de equipe, Malu, fizeram a publicidade do produto fabricado ao público feminino (FUTEBOL..., 24 fev. 1984), como mostra a imagem:

Figura 6 - Publicidade de Chuteiras

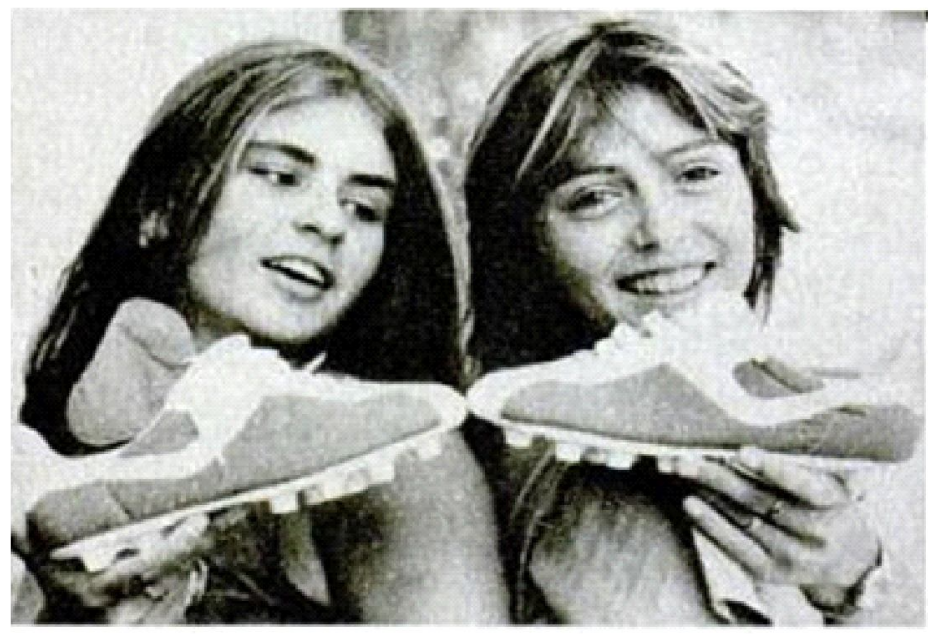

Fonte: Revista Placar, 24 fev. 1984

\begin{abstract}
${ }^{8}$ Luciano do Valle, locutor esportivo da atual Band e antiga TV Bandeirantes, foi e é conhecido no meio futebolístico como grande fomentador do futebol feminino. Atualmente ele apoia e patrocina a equipe de Foz do Iguaçu - PR (Foz Cataratas) que encerrou o ano de 2011 vencendo - Campeonato Paranaense e a Copa do Brasil. Essa equipe conta com jogadoras que já estiveram no NMFC e foram em busca de melhores condições financeiras e de treinamento. A J.Cocco Sport Marketing, em parceria com Luciano do Valle, promovem desde 2007 um programa de incentivo ou futebol feminino intitulado: Futebol Mulher - A nova paixão brasileira. Mais informações estão disponíveis em: <http://www.lucianodovalle.com.br/Releases/ FutebolMulherRelease001.asp?P=>. Acesso em: 2 ago. 2011.
\end{abstract}


Com exceção do uniforme que teve seu design modificado com o passar dos anos, curiosamente, não encontramos relatos da criação de outros produtos especiais para as mulheres, ato que nos leva a crer que não haveria necessidade de oferta, tendo em vista que a demanda também era restrita. É necessário lembrar, para que ocorram transformações nas práticas e consumos esportivos é preciso que ocorram transformações tanto da oferta quanto da demanda, que se baseiam em diferentes lutas. As transformações da oferta estão vinculadas às práticas esportivas legítimas e pela conquista de diferentes clientes, já as transformações da demanda, estão diretamente ligadas às transformações no estilo de vida (BOURDIEU, 1983).

Nesse contexto ao analisarmos as transformações necessárias para a alteração da oferta, o futebol feminino ainda não era (e não tem dado indícios mesmo atualmente que é) uma prática legítima, fator que influencia negativamente a conquista de uma nova clientela. Já as transformações da demanda, são um tanto quanto mais complexas, pois estão estreitamente relacionadas ao habitus ${ }^{9}$ das agentes praticantes ou futuras praticantes do futebol feminino, trazendo a tona todo o emaranhado de significados e significações que a modalidade esboça no Brasil na década de 1980.

Outro elemento importante reforçado pela mídia, é que na década de 1980 a beleza física e a sensualidade, enquanto atributos femininos estavam mais atrelados ao futebol do que a habilidade esportiva propriamente dita. Sendo assim, tecnologias específicas que visassem melhor desempenho não obtinham êxito com esse público.

Num sentido compensatório entre futebol e beleza ou beleza e futebol, a matéria alude que: "de currículo futebolístico pouco mais de medíocre, o Internacional, de Porto Alegre, é indiscutivelmente o campeão nacional de beleza" (FUTEBOL..., 1984, p. 24). Ou seja,

\footnotetext{
${ }^{9}$ Para Bourdieu (1996) habitus diz respeito a um corpo socializado, um corpo estruturado, um corpo que incorporou as estruturas imanentes de um mundo ou de um setor particular desse mundo, de um campo, e que estrutura tanto a percepção desse mundo como a ação nesse mundo.
}

Movimento, Porto Alegre, v. 19, n. 01, p. 95-115, jan/mar de 2013. 
a beleza física supre a falta de habilidade. Ainda em se tratando de clubes gaúchos (Internacional e Grêmio), esses assumiam características diferenciadas com relação as suas jogadoras, não ofertavam nem salários e nem auxílio com os custos que as jogadoras tinham para se deslocar até o local de treinamento.

Situação diferente já se encontrava em equipes de São Paulo (SAAD, São Paulo), do Rio de Janeiro (Bangu, Vasco, Radar), do Paraná (Pinheiros e Colorado), da Bahia (Clube Baiano de Tênis) e também de Minas Gerais (América e Atlético Mineiro), nas quais, as jogadoras recebiam - ao menos - uma ajuda de custo para o transporte até o clube ou salários. É importante destacar o anseio do Esporte Clube Radar em assumir uma postura mais profissional ao tratar da gestão do futebol feminino no clube.

Frente a esse panorama e de acordo com a revista Placar, as jogadoras demonstravam grande interesse em participar do "possível" Campeonato Mundial de Futebol Feminino a ser realizado pela FIFA no ano de 1987 no Japão ${ }^{10}$. Especialmente as meninas do Esporte Clube Radar, que em 1982 foram as primeiras mulheres latinoamericanas a pisarem em campos de futebol europeus.

Embora o Esporte Clube Radar se diferenciasse - em termos de organização e gestão esportiva - dos outros clubes brasileiros, os salários ainda eram inferiores ao valor pago para as "Globetes", nome do time formado por atrizes da Rede Globo. Na edição de 8 de abril de 1988, a revista Placar apresentou uma pequena sessão dedicada a Isadora Ribeiro, a "garota da abertura do fantástico", Globete há dois anos. "Com a bola nos pés, ela é uma negação completa. [...] ninguém vaia quando ela erra um passe ou perde um gol. [...] As Globetes se preocupam apenas em dar um autêntico show de beleza no gramado" (É FANTÁSTICA, 1988, p. 53). A foto a seguir evidencia a sensualidade feminina vinculada à bola de futebol, bem como, a propaganda do time impressa na camisa da Globete, que não lembra em nada as camisas dos uniformes esportivos.

\footnotetext{
${ }^{10} \mathrm{Com}$ base no site da FIFA, o Mundial de Futebol Feminino de 1987 previsto para ser realizado no Japão não ocorreu.
} 
Figura 7 - Globete
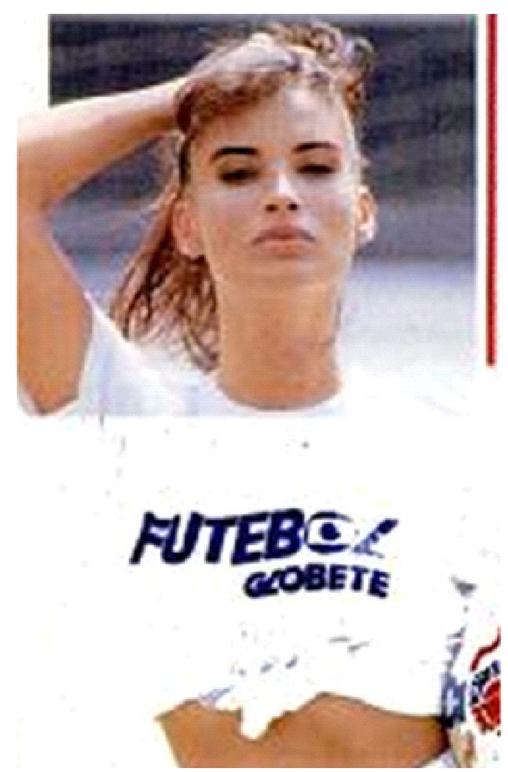

Fonte: Revista Placar, 8 abr. 1988

A revista Placar (FUTEBOL..., 1984, p. 27) retrata que as "Globetes" foram convidadas pela Presidência da República para inaugurar o campo de futebol da Granja do Torto, mas "são ruins de bola, cruzaram com o Radar uma vez e perderam de 12X0". Ainda nesse ano a revista Placar destinou quatro páginas ao futebol feminino, com destaque para a equipe do Esporte Clube Radar. Nessa edição (de $\mathrm{n}^{\circ}$ 744), com matéria intitulada "Futebol Feminino: O Charme $^{11}$ da Conquista" abordou questões relacionadas ao processo de "feminilização" antes dos jogos.

Rosa, Margarete e Valerinha, do Radar, ficam horas diante do espelho quando vão entrar em campo. [...] Vavi, do São Paulo, usa fitinha no cabelo e faz questão de se maquiar no vestiário. As garotas do

\footnotetext{
${ }^{11}$ Assim como retratamos anteriormente, a escolha das palavras remete a um contexto feminino. Tendo em vista a construção cultural e histórica dos gêneros pautado nos papéis e nas disposições para a ação no contexto social.
} 
Internacional fazem fila diante do espelho e disputam pentes e escovas de cabelo com a mesma disposição com que vão numa dividida. [...] Quase todas as artistas da bola, incluindo as meninas do Atlético Mineiro - que usam uniforme igual ao dos jogadores, até com sunga -, não curtem muito a ideia de jogar com sutiã, como manda a lei (FUTEBOL..., 1984, p. 42).

Evidenciamos nesse momento que embora a temática, beleza e feminilidade estivessem permeando a matéria de modo geral, as fotos veiculadas nesse momento são de situações de jogo/treino ou de demonstrações de habilidade das futebolistas com a bola e principalmente a possibilidade de profissionalizar o futebol feminino, desejo suscitado devido à excelente campanha do Esporte Clube Radar.

Após aproximadamente um ano, mais uma publicação sobre o futebol feminino circulava em território nacional. No dia $1^{\circ}$ de fevereiro de 1985 a edição no 767 da revista Placar reservou três páginas para escrever sobre o Esporte Clube Radar. "As Invencíveis: O Radar, um time que só perdeu dois jogos na vida, quer agora ser campeão do mundo". Nessa ocasião foram apresentadas as 11 jogadoras do clube, incluindo a idade, o peso, a altura, o número da chuteira, o tamanho do busto, a posição em campo, a principal característica de jogo e o salário.

A presente matéria abordou também, a qualidade técnica e principalmente o preparo físico das jogadoras, enfatizando que estavam treinando em regime de concentração há um ano na Casa do Marinheiro, e costumavam fazer coletivos contra um time de marujos. Ficou perceptível nessa edição que a atenção principal foi voltada para a veiculação das informações relacionadas às habilidades da modalidade em detrimento aos atributos físicos na conotação estética ou feminina.

Darido (2002) assinala que as vitórias do Esporte Clube Radar estimularam o nascimento de novos times e, em 1987, a CBF já 
havia cadastrado 2 mil clubes e 40 mil jogadoras. Considerada disparada - a equipe destaque na década de 1980, o Esporte Clube Radar colecionou títulos nacionais e internacionais.

Até paralisar suas atividades no ano de 1988, o Esporte Clube Radar realizou mais de 300 partidas, sendo 71 delas no exterior, obtendo 66 vitórias, 03 empates e 2 derrotas. Tendo como performances nos principais eventos: Campeão da Divisão Feminina do Rio de Janeiro de 1983 a 1988; Campeão Brasileiro de 1984 a 1988; Campeão do I Torneio Brasileiro de Clubes; Terceiro colocado no I Torneio Internacional de Futebol Feminino na cidade de Cabo Frio; Campeão do Women Cup Of Spain; e $3^{\circ}$ lugar representando o Brasil no I Torneio Internacional de Futebol Feminino na China (FERNANDES, 1991).

O campeonato de 1988 foi o último disputado pelo Esporte Clube Radar, fato que marcou a decadência da equipe, como também, a do futebol feminino brasileiro de modo geral. Dentre as principais equipes que durante toda a década de 1980 investiram em times fortes, algumas "fecharam as portas" e outras desistiram de apoiar o futebol feminino (DARIDO, 2002). Contudo, Valporto (2006) afirma que mesmo com escasso incentivo, as ligas amadoras continuaram existindo.

\section{ConclusÃo}

Como marca dessa década, na qual o futebol feminino foi "presenteado" com permissão documental da prática, temos o curto ciclo de existência do Esporte Clube Radar, que ficou historicamente conhecido pela campanha de vitórias. Ao lado desse acontecimento, sublinhamos o anseio da mídia em veicular o futebol feminino sempre associado ao ser feminino enquanto construção social de gênero pautado na sexualidade.

Mesmo que de forma discreta ou mascarada por fotos sensuais ou por ações "femininas" como usar maquiagem, a homossexualidade 


\section{Artigos Originais}

era tema recorrente. Entendemos que por ser recente a permissibilidade oficial da prática do futebol pelas mulheres, ainda apresentava uma grande quantidade de resquícios da proibição e da associação da mulher futebolista ao homossexualismo. Desse modo, o investimento se deu em circular informações e representações que relacionassem a imagem das futebolistas aos ideais de feminilidade, visando desmistificar a polêmica homossexual que rondava a prática do futebol feminino no Brasil.

De maneira geral, podemos concluir que as informações veiculadas pela revista Placar são organizadas basicamente em três principais elementos. Inicialmente apresentam informações relacionadas a proibição e permissibilidade da prática do futebol pelo público feminino; posteriormente, a revista veicula matérias abordando a habilidade feminina para jogar futebol, frisando principalmente o surgimento a performance do Esporte Clube Radar; e finalizando, um tema que permeia os elementos anteriores e é recorrente nessa fase da revista, são as matérias que exaltam as características de feminilidade normativa nas jogadoras de futebol. 
An history of female soccer on the pages of Placar Magazine between 1980 - 1990

Abstract: The present article aims to present an history of female soccer told by the pages of Placar magazine between 1980 - 1990. Were mapped 457 copies, these, 8 were used to develop this article. After analyzing the data, we noticed that in this decade three main information about soccer were conveyed on the magazine: 1.)permissibility of soccer practicing by the female audience; 2)the female ability to play soccer, stressing mainly the emergence of Esporte Clube Radar performing; e 3)a theme that permeates in this phase of the magazine, are the ones that exalt the characters of normative femininity on female soccer players.

Keywords: Placar Magazine. Female Soccer. History of Female Soccer.

\begin{abstract}
Una historia del fútbol femenino en las paginas de la Revista Placar entre los años 1980 - 1990

Resumen: Este trabajo tiene como objetivo presentar una historia del fútbol femenino contada por medio de las páginas de la revista Placar entre los años 1980 y 1990. 457 copias fueron asignadas cuales 8 fueron utilizados para desarrollar este artículo. Después de analizar los datos, observamos que en esta década las mayores informaciones sobre el fútbol femenino se publicaron en la revista fueron: 1) la permisibilidad de la práctica del fútbol por el público femenino, 2) la capacidad de las mujeres para jugar al fútbol, destacando principalmente el surgimiento del Esporte Clube. Radar, y 3 ) un tema que impregna el fondo y es recurrente en esta etapa de la revista, son las materias que exaltan las características de la feminidad normativa en futbolistas femeninas.
\end{abstract}

Palabras-clave: Revista Placar. Fútbol femenino. Historia del Fútbol Femenino. 


\section{ArtigosOriginais}

\section{REFERÊNCIAS}

BOLA (também) é para mulher. Placar, São Paulo, n. 672, 8 abr. 1983.

BOURDIEU, P. Questões de sociologia. Rio de Janeiro: Marco Zero, 1983.

Razões práticas. Campinas: Papirus, 1996.

Sobre a televisão. Rio de Janeiro: Zahar, 1997.

BRASIL. Decreto-lei no 3.199, de 14 de abril de 1941. Disponível em: <http:// www6.senado.gov.br/legislacao/ListaPublicacoes.action? id=152593>. Acesso em: 09 set. 2010.

Lei $n \times$ 6.251, de 8 de outubro de 1975. Disponível em: <http:// www3.dataprev.gov.br/SISLEX/paginas/42/1975/6251.htm>. Acesso em 09 set. 2010.

CARMONA. L.; POLL, G. Almanaque do futebol. Rio de Janeiro: Casa da Palavra, 2006.

DAMO, A. S. Futebol e identidade social: uma leitura antropológica das rivalidades entre torcedores e clubes. Porto Alegre: Editora da UFRGS, 2002.

DARIDO, S. C. Futebol feminino no Brasil: do seu inicio à prática pedagógica. Motriz, Rio Claro, v. 8, n. 2, p. 43-49, 2002.

É FANTÁSTICA!. Placar, São Paulo, n. 931, 8 abr. 1988.

FERNANDES, A. K. A história do futebol feminino na cidade do Rio de Janeiro. Monografia (Especialização em futebol) - Universidade Federal do Rio de Janeiro, Rio de Janeiro, 1991. Disponível em: <http://www.sintrefutrj.com.br/ historiafutfemininoandrea.pdf>. Acesso em: 10 ago. 2011.

FRANZINI, F. Futebol é "coisa para macho"?: pequeno esboço para uma história das mulheres no país do futebol. Revista Brasileira de História, São Paulo, v. 25, n. 50, p. 315-328, 2005.

FUTEBOL é para mulher! Placar, São Paulo, n. 509, 1ํ fev. 1980.

FUTEBOL feminino: o charme da conquista. Placar, São Paulo, n. 718, 24 fev. 1984.

FUTEBOL feminino: as incríveis meninas do Radar. Placar, São Paulo, n. 767, 1 fev. 1985.

GOELLNER, S. V. Imperativos do ser mulher. Motriz, Rio Claro, v. 5, n. 1, p. 40-42, 1999.

- Mulher e esporte no Brasil: entre incentivos e interdições elas fazem história. Pensar a Prática, Goiânia, v. 8, n. 1, p. 85-100, 2005. 
O esporte e a espetacularização dos corpos femininos. Labrys: Estudos Feministas, Florianópolis, n. 4, ago./dez. 2003.

MINHA opinião. Placar, São Paulo, n. 594, 2 out. 1981.

MOURÃO, L. Representação social da mulher brasileira nas atividades físicodesportivas: da segregação à democratização. Movimento, Porto Alegre, n. 13, p. 5-18, 2000.

AS MULHERES invadem o campo: 3000 times. Placar, São Paulo, n. 738, 13 jul. 1984.

RIGO, L. C. et al. Notas acerca do futebol feminino pelotense em 1950: um estudo genealógico. Revista Brasileira de Ciências do Esporte, Campinas, SP, v. 29, n. 3, p. $173-188$, maio 2008.

UM TIME só de estrelas. Placar, São Paulo, 593, 25 set. 1981.

VALPORTO, O. Atleta, substantivo feminino: vinte mulheres brasileiras nos jogos olímpicos. Casa da Palavra, Rio de Janeiro, 2006.

VEJA. São Paulo: ed. Abril, n. 811, 21 mar, 1984.

TOLEDO, L. H. de. No país do futebol. Rio de Janeiro: Zahar, 2000.

Endereço para correspondência:

Leila Salvini

Rua Curitiba, 222

Bairro Santo Antônio

Pinhalzinho/SC

89870-000

Recebido em: 19.08.2012

Aprovado em: 31.10 .2012

Movimento, Porto Alegre, v. 19, n. 01, p. 95-115, jan/mar de 2013. 